\title{
Effect of Activebag® Modified Atmosphere Packaging on the Postharvest Characteristics of Mango Fruits, Mangifera indica L, Cultivar Tommy Atkins
}

\author{
Githiga, Ruth ${ }^{*}$, Ambuko, Jane ${ }^{1}$, Margaret, Hutchnison ${ }^{1}$ and Willis, Owino ${ }^{2}$ \\ 1 University of Nairobi, Department of Plant Science and Crop Protection P.O Box 29053-00625, Nairobi \\ 2Jomo Kenyatta University of Agriculture and Technology, Department of Food Science and Postharvest Technology \\ P.O Box 62000-00100, Nairobi \\ *Corresponding author, Email: githigaruth@gmail.com
}

Original submitted in on $5^{\text {th }}$ May 2014. Published online at www.m.elewa.org on 30 http://dx.doi.org/10.4314/jab.v83i1.6

\begin{abstract}
Objective: This was to evaluate the efficacy of MAP in maintaining the postharvest quality of mango fruits. Methodology and results: The fruits were harvested from a commercial orchard, (Karurumo Orchards) located in Embu county of Eastern province. The fruits were harvested at advanced maturity during the pre-climacteric rise phase when most of the flesh had turned yellow. They were selected for uniformity in colour, size and shape and randomly separated into three equal batches of 50 fruits each. The first batch was packaged in Activebag®, second batch in ordinary (commercially used) polythene bags while the third batch was left unpackaged as control. Five fruits from each treatment were sampled every three days during the shelf life period and evaluated for various physiological and physicochemical parameters associated with mango ripening and quality including ethylene evolution, respiration rate, cumulative weight loss, firmness, hue angle, total soluble solids, total titratable acid, soluble sugars, ascorbic acid and beta-carotene. MAP whether in Activebag® or ordinary polythene was effective in maintaining the quality of mango fruits compared to the unpackaged controls. Slow ripening changes of Activebag® fruits was accompanied by a delayed respiratory climacteric and generally lower respiration rates compared to ordinary bag and unpackaged fruits. At the end of the observation period, Activebag $®$ fruits were $16 \%$ firmer compared to unpackaged fruits. The initial average weight was $635 \mathrm{~g}$ and modified atmosphere packaging had a remarkable effect on cumulative weight loss with fruits packaged in the ordinary polythene bag and Activebag $®$ fruits losing only $7.4 \%$ of the initial weight compared to $12 \%$ in the case of unpackaged fruits (control). Higher levels of total soluble solids ( ${ }^{\circ}$ brix) $5.5 \mathrm{~g} / 100 \mathrm{~g}$ and total soluble sugars $(6 \mathrm{~g} / 100 \mathrm{~g})$ observed at the beginning of storage (6 days after packaging) signalled advanced ripening of unpackaged fruits. However as the storage time progressed, the levels of each of the soluble sugars evaluated were higher in Activebag® fruits. Similarly, Activebag $®$ fruits retained higher levels of titratable acidity ( $0.39 \%$ and ascorbic acid compared to ordinary bag fruits $(0.36 \%)$.

Conclusion: Packaging mangoes in Activebag $®$ after harvest at ripe stage was effective in delaying most of the ripening related changes in mango fruits thereby maintaining the quality and extending their shelf life. Although ordinary polythene packaging maintained quality of the fruits better than unpackaged fruits, the positive effects were negated by high incidences of rotting.
\end{abstract}

Key words: Mango, MAP, postharvest, quality, shelf life 


\section{INTRODUCTION}

Mango fruit(Tommy Atkins) is highly perishable with a short postharvest life which depends on harvest maturity and storage conditions (Slaughter, 2009). Their high perishability leads to high post harvest losses and reduces realization of the commercial potential of mangoes. Deterioration of harvested mango fruits is attributable to various biological factors such as respiration and ethylene production as well as environmental factors like temperature and relative humidity. Management of the factors that predispose mango fruits to deterioration in the postharvest continuum is critical in maintaining quality. Several strategies have been used to slow down deteriorative processes in harvested fruits, which include low temperature storage, low-pressure storage, controlled atmosphere storage, modified atmosphere storage/packaging and ethylene management. The selection and application of either of these strategies depends on the efficacy, versatility and relative value of the commodity (Prusky and Keen, 1993). Modified atmosphere packaging (MAP) is a simple postharvest technology. It involves packaging actively respiring produce in polymeric film packages to modify the $\mathrm{O}_{2}$ and $\mathrm{CO}_{2}$ levels within the package atmosphere. The modified atmosphere affects physicochemical and physiological processes in fruits positive or negative effects (Valero and Serrano, 2010). Some of the beneficial effects of MAP include delayed ripening by inhibiting the production of ethylene, reduced transpiration water loss, delayed biochemical activities associated with ripening and increased resistance to the attack of postharvest pathogens (Prusky and Keen, 1993). Weight loss is one of the major problems in harvested fruit leading to loss of saleable weight and shrivelling thereby affecting marketability and quality of the fruits. Transpiration water loss in harvested commodities is also associated with loss of watersoluble vitamins including vitamin C (Valero and Serrano, 2010). Polymeric films used in MAP hinder water vapour diffusion and as a result, the internal atmosphere package becomes saturated with water vapour pressure thereby reducing transpiration of the tissues and the resultant weight loss. The low $\mathrm{O}_{2}$ atmosphere created in MAP also affects physiological processes including respiration and ethylene biosynthesis and action. Reduced respiration rates associated with low oxygen atmosphere in turn slows down starch degradation and sugar consumption in packaged commodities. Use of MAP in climacteric fruits such as mango, apart from reduction of respiration rate, delays climacteric respiration (Yahia, 2006; Singh and Rao, 2005). In addition, conditions created in MAP (low $\mathrm{O}_{2}$ and high $\mathrm{CO}_{2}$ ) interfere with ethylene biosynthesis by hindering activity of 1-Aminocyclopropane-1carboxylic acid (ACC) oxidase, the enzyme that catalysis the conversion of ACC to ethylene. It has also been shown that $\mathrm{CO}_{2}$ is an antagonist of ethylene action and impedes its autocatalytic synthesis (Yang and Hoffman, 1984). Matching commodities' physiological characteristics with those of the package is critical in attaining the beneficial effects of MAP. Recent advances in MAP have led to the design and manufacture of polymeric films with a wide range of gas permeability characteristics to cater for different commodities with varied physiological attributes. Efficacy of such polymeric films is further enhanced through impregnation with ethylene, oxygen and carbon dioxide absorbers and anti-microbial compounds. One such package is the 'Activebag ${ }^{\circledR}$ ', a flexible polymeric package that utilizes unique antimicrobial materials that preserves freshness and prevents spoilage, substantially increasing the storage and shelf-life of perishable commodities (Omry, 2011). Therefore the objective of the present study, was to compare the effect of Activebag ${ }^{\circledR}$ a new polymeric film introduced in the Kenyan market, with commonly used polythene bags on postharvest characteristics of 'Tommy Atkins' mango fruits harvested at an advanced maturity stage with full cheeks, a sunken stem end and the flesh was mostly yellow-orange in colour. 


\section{MATERIALS AND METHODS}

Mango fruits were harvested from a commercial orchard, Karurumo Orchard Limited, located in Embu County, Eastern Kenya. The fruits that were harvested at advanced maturity had full cheeks, a sunken stem end and the flesh was mostly yellow-orange in colour. Physiologically, the fruits were at the pre-climacteric rise phase where respiration rate had started rising towards the peak and autocatalytic ethylene production had commenced. The fruits were carefully handpicked during and packed into plastic crates lined with wetted papers as cushioning materials to protect them from mechanical injury during transport as well as reduce the respiration rate. On arrival to the Laboratory,-the fruits were immediately washed in cold water treated with $1 \%$ acetic acid to disinfect and disinfest. The fruits were dried on open shelves at room temperature and then selected for uniformity and freedom from blemishes or mechanical injuries. The selected fruits were then randomly separated into three batches of 50 fruits each for administration of the MAP treatments namely ordinary polythene bags (used commercially) and Activebag $\circledR$ (a newly introduced MAP product). The third batch was left unpackaged to act as the control. The fruits were then stored on trays at ambient conditions (temperature; $25 \pm$ $1^{\circ} \mathrm{C}$ and $\mathrm{RH} 60 \pm 5 \%$ ) to undergo normal ripening. Five fruits from each batch were randomly sampled (every 3 days) as replicates for evaluation of changes associated with ripening which included loss in firmness, loss in hue angle, cumulative weight loss, ethylene evolution and respiration rates, soluble sugars, soluble solids, titratable acidity, ascorbic acid and beta carotene. The experimental design used was a completely randomized

\section{RESULTS}

All the fruits gradually lost weight during storage although the cumulative weight loss in unpackaged control was significantly high $(p=0.05)$ compared to the packaged fruits. The initial average weight was $635 \mathrm{~g}$, at the end of the storage, unpackaged fruits had lost $11.8 \%$ of the initial weight compared to $7.2 \%$ and $7.3 \%$ in Activebag ${ }^{\circledR}$ and ordinary bag fruits respectively. No significant differences were observed between Activebag $\otimes$ and the ordinary bag (Fig. 1). Packaging had a significant effect ( $p$ $=0.05$ ) on the rate of respiration with packaged fruits (Activebag $®$ and ordinary bag) exhibiting significantly low respiration rates compared to unpackaged fruits throughout the storage period. In unpackaged fruits respiration peak (140 ml/kg/hr) occurred on day 6 whereas design (CRD). Firmness was measured along the equatorial region of the sampled fruits using a penetrometer (Model CR-100D, Sun Scientific Co. Ltd, Japan). Colour of both the pulp and peel were measured using a Minolta Colour Difference Meter (Model CR-200, Osaka, Japan) and expressed as hue angle in degrees. Ethylene production and respiration rates were determined using gas chromatographs Models GC-8A and GC-9A, Shimadzu Corp., Kyoto, Japan, respectively. Soluble sugars (Sucrose, fructose and glucose) were analyzed using a high performance liquid chromatograph (HPLC) (Model LC-10AS, Shimadzu Corp., Kyoto, Japan) fitted with a refractive index (RI) detector using AOAC method (1996) achieved with mobile phase acetonitilewater (80:20). Total soluble solids (TSS) content was determined using an Atago Hand Refractometer (Model 500, Atago, Tokyo, Japan) and expressed as ${ }^{\circ}$ Brix. Total titratable acidity (TTA) was determined by titration with $0.1 \mathrm{~N} \mathrm{NaOH}$ in the presence of phenolphthalein indicator. The TTA is expressed as \% citric acid, the predominant organic acid in mango fruit (Ueda et al., 2000). Ascorbic acid was determined using the AOAC (1996) method where five grams of the pulp were ground and diluted with $10 \%$ trichloroacetic acid (TCA) to 100 mark of a $100 \mathrm{ml}$ volumetric flask. 2, 6-dichlorophenolindophenol was titrated to $10 \mathrm{ml}$ of the fruit pulp filtrate. Ascorbic acid content was expressed in $\mathrm{mg} / 100 \mathrm{~g}$. Beta-carotene was determined by modified chromatographic procedure and beta-carotene level determined using UV-Vis spectrophotometer (Model UV mini 1240, Kyoto Shimadzu) and absorption at $450 \mathrm{~nm}$.

the significantly smaller respiratory peak (120 and 98 $\mathrm{m} / \mathrm{Kg} / \mathrm{hr}$ ) for ordinary bag and Activebag $囚$ respectively was delayed by 3 days, to occur on day 9 . At the end of the storage period there was no difference in the respiration rates of packaged and unpackaged fruits (Fig. 2).Ethylene evolution was erratic throughout the storage period and no clear trends were observed in both the unpackaged and packaged fruits. No ethylene was detected in all the fruits from the initial period until day 6 of storage where small peaks of 41.3 and $47.5 \mathrm{n} / / \mathrm{Kg} / \mathrm{Hr}$ were observed in ordinary bag and Activebag ${ }^{\circledR}$ respectively. On the $7^{\text {th }}$ day of storage, larger peaks: 207 $\mathrm{nl} / \mathrm{Kg} / \mathrm{Hr}$ (unpackaged), $121.4 \mathrm{nl} / \mathrm{Kg} / \mathrm{Hr}$ (Activebag ${ }^{\circledR}$ ) and $62.5 \mathrm{nl} / \mathrm{Kg} / \mathrm{Hr}$ (ordinary bag) were observed. 


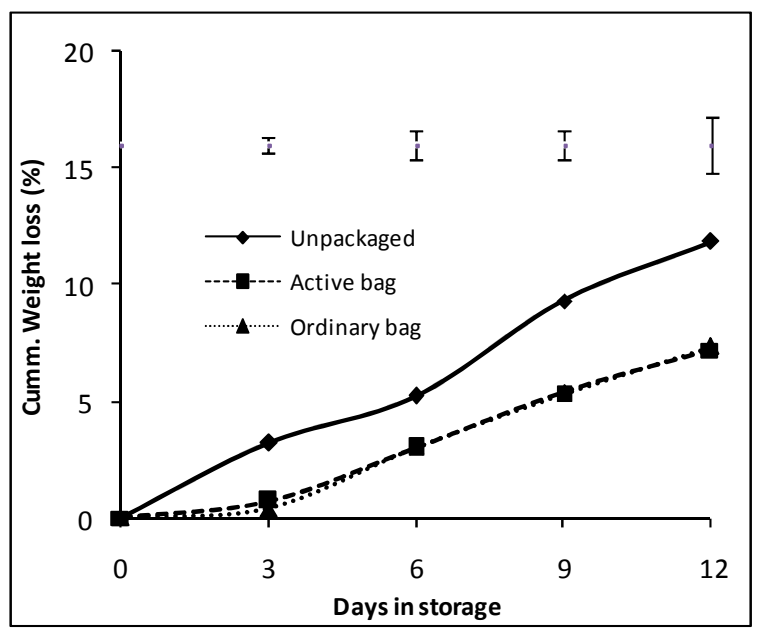

Figure 1: Cumulative weight loss of 'Tommy Atkins' mango fruits which were left unpackaged (control), packaged in ordinary polythene bags or Activebag®.Top bars show the least significant difference (LSD) of five means at each day of storage $(p=0.05)$.

The peel firmness of fruits packaged in Activebag $®$ remained firmer throughout storage period compared to unpackaged fruits and those in ordinary bags. Although fruits in ordinary bag showed significant difference with the unpackaged on the $3^{\text {rd }}$ day of storage, after day 6 until end of storage no significant difference were observed between the unpackaged fruits and ordinary bag fruits. By the end of storage (day 12) Activebag ${ }^{\circledR}$ fruits were $16 \%$ firmer at $9.3 \mathrm{~N}$ compared to the ordinary bag and unpackaged fruits' firmness of $5.4 \mathrm{~N}$ and $3.5 \mathrm{~N}$ respectively (Fig 3A). Flesh firmness exhibited a similar trend to the peel firmness with a gradual decrease in firmness occurring in all the fruits. Just as in the peel, fruits packaged in Activebag $®$ retained higher flesh firmness throughout storage period compared to unpackaged fruits and those in ordinary bags. No significant difference in flesh firmness between the ordinary bag and unpackaged was observed, except on the $3^{\text {rd }}$ day of storage. By the end of storage (day 12) Activebag $\circledast$ fruits remained firmer $(5.2 \mathrm{~N}$ ) compared to the ordinary bag and unpackaged fruits whose firmness was less than half that of Activebag $®$ at $2.3 \mathrm{~N}$ (Fig 3B).

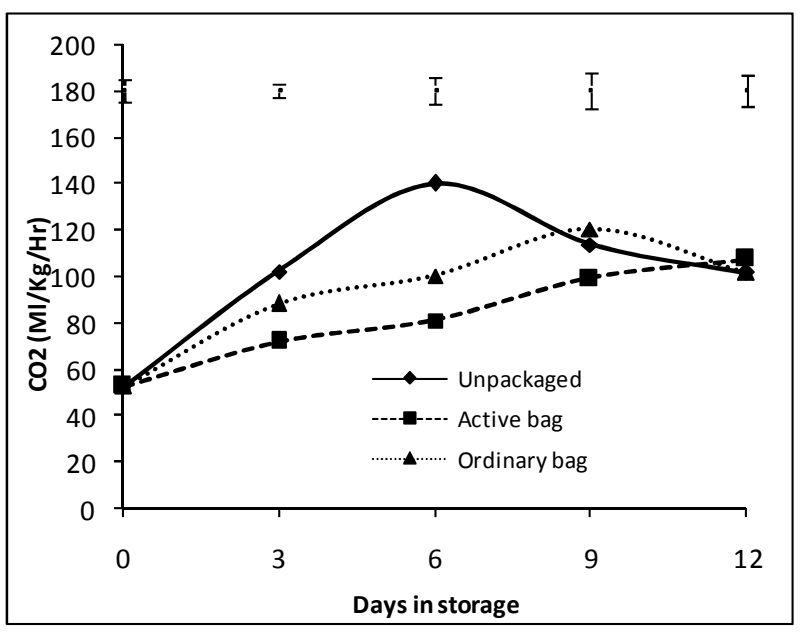

Figure 2: Changes in respiration rates of 'Tommy Atkins' mango fruits which were left unpackaged (control), packaged in ordinary polythene bags or Activebag®.Top bars show the least significant difference (LSD) of five means at each day of storage $(p=0.05)$.

Both peel and flesh colour as measured by hue angle decreased gradually in all fruits as they ripened. Peel colour change from green to yellow was significantly slowed down by packaging, with the effect being more evident in Activebag ${ }^{\circledR}$ fruits. Peel colour change progressed rapidly in unpackaged fruits from the initial $106^{\circ}$ to $64^{\circ}$ at the end of storage (day 12). The decreased in hue angle was less gradual in packaged fruits while Activebag $®$ fruits retaining a high hue angle throughout the storage period. At the end of storage, fruits packaged in Activebag ${ }^{\circledR}$ had the highest hue angle $88^{\circ}$, a $17 \%$ reduction from the initial hue angle value compared to the $40 \%$ reduction in hue angle observed in unpackaged fruits (Fig. 4A). A similar trend was observed in the flesh colour where the hue angle decreased as the intensity of the yellow-orange colour increased with storage time (Fig. 4B). Hue angle decreased from an initial $106^{\circ}$ to $65^{\circ}$ in unpackaged fruits compared to $78^{\circ}$ of fruits packaged in Activebag $\circledast$ at the end of storage. This represented a $39 \%$ and $26 \%$ reduction in hue angle in Activebag ${ }^{\circledR}$ and unpackaged fruits respectively. 

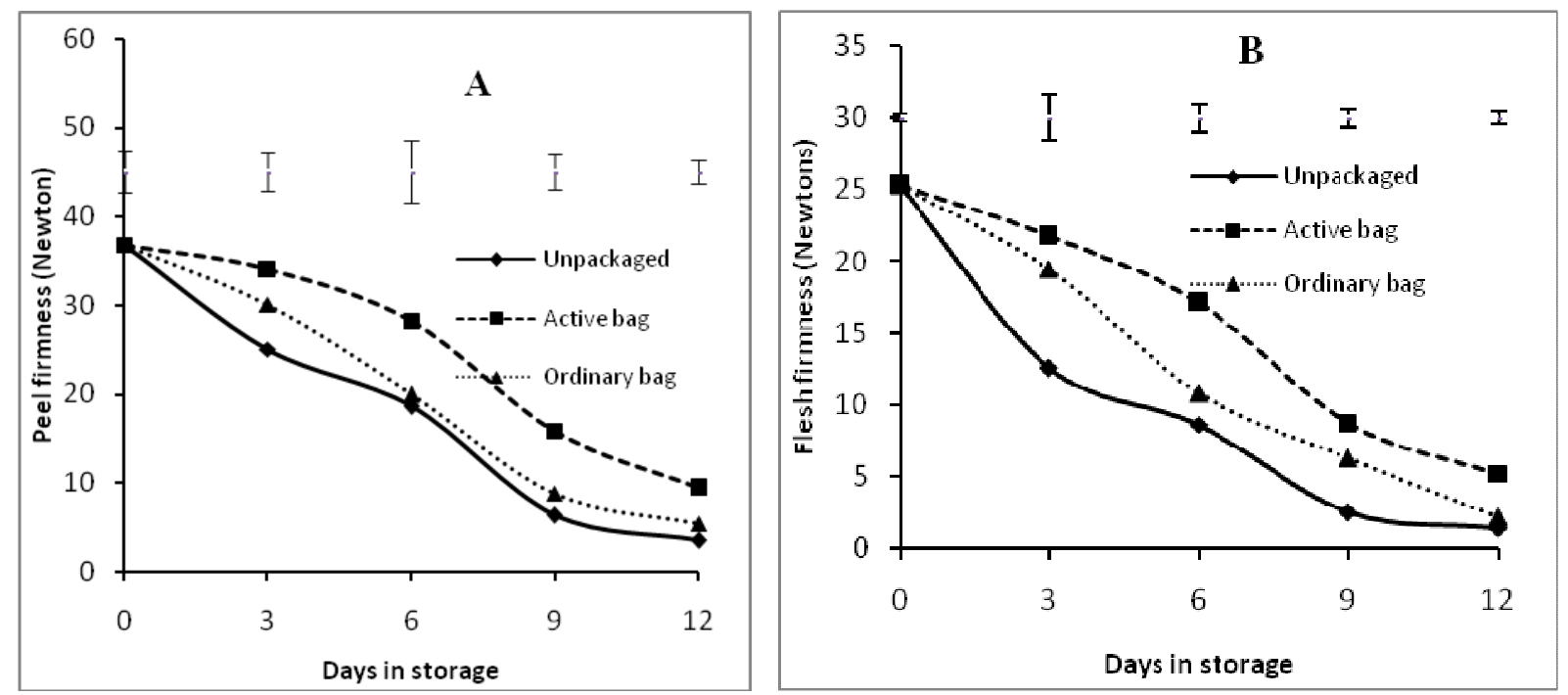

Figure 3:Changes in Peel firmness (A) and flesh firmness (B) Tommy Atkins' mango fruits which were left unpackaged (control), packaged in ordinary polythene bags or Activebag $®$. Top bars show the least significant difference (LSD) of five means at each day of storage $(p=0.05)$.
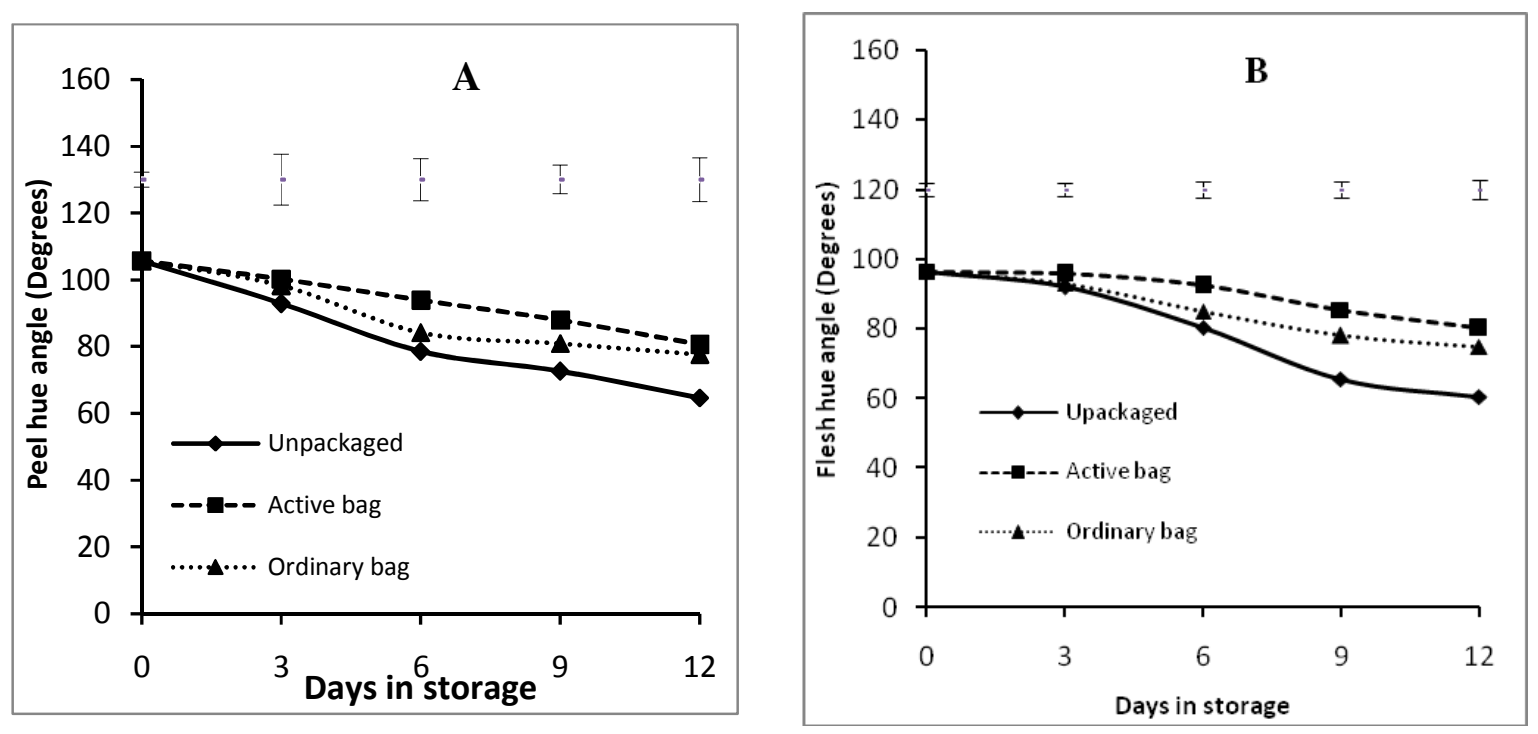

Figure 4: Changes in Peel hue angle $(A)$ and flesh hue angle $(B)$ of 'Tommy Atkins' mango fruits which were left unpackaged (control), packaged in ordinary polythene bags or Activebag ${ }^{\circledR}$. Top bars show the least significant difference (LSD) of five means at each dav of storaae $(\mathrm{D}=0.05)$. 

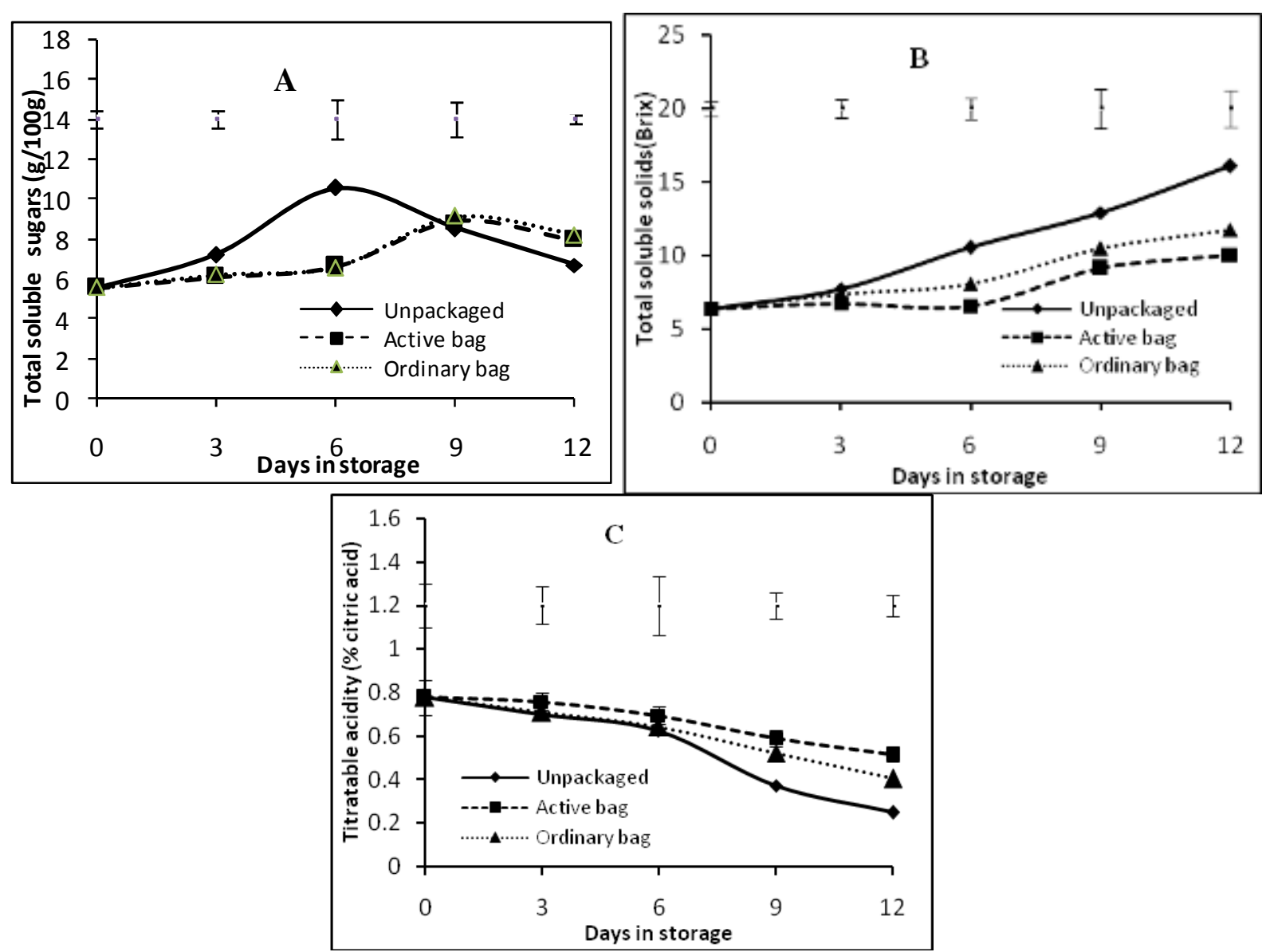

Figure 5: Changes in total soluble sugars content (A), total soluble solids $(B)$ and titratable acidity $(C)$ of 'Tommy Atkins' mango fruits which were left unpackaged (control), packaged in ordinary polythene bags or Activebag $囚$. Top bars shows least significant difference (LSD) of five means at each dav of storade $(\mathrm{D}=0.05)$.

A gradual increase in soluble sugars was observed in all the fruits as they ripened. In unpackaged fruits, the total soluble content increased from an initial $5.5 \mathrm{~g} / 100 \mathrm{~g}$ to a peak of $10.5 \mathrm{~g} / 100 \mathrm{~g}$ on the 6th day of storage and thereafter reduced gradually to $6.6 \mathrm{~g} / 100 \mathrm{~g}$ at the end of the storage period (Fig. 5A). The changes in soluble sugars exhibited a similar trend for the fruits packaged in Activebag ${ }^{\circledR}$ and ordinary bags. The sugars remained relatively low until after the 6 th day of storage when there was a gradual rise to a peak level of $9.1 \mathrm{~g} / 100 \mathrm{~g}$ on day 9 and thereafter a slight decrease to $8.2 \mathrm{~g} / 100 \mathrm{~g}$ at the end of the storage period. The decrease occurred more rapidly in unpackaged fruits where by the $6^{\text {th }}$ day the TTA had reduced significantly and at the end of the storage period, TTA level was $0.24 \%$ citric acid down from the initial levels of $0.77 \%$ citric acid equivalent. The packaged fruits retained relatively higher levels of TTA compared to the unpackaged fruits. At the end of the storage period, the fruits packaged in Activebag $\circledast$ had the highest levels of TTA $0.51 \%$ citric acid equivalent, a $33 \%$ decrease from the initial TTA levels. Levels of vitamin $C$ decreased with storage time in both packaged and unpackaged fruits. There was significant packaging effect on vitamin $\mathrm{C}$ reduction rate. The unpackaged fruits showed a significant decrease in vitamin $C$ at the end of the storage period from the initial $53 \mathrm{mg} / 100 \mathrm{~g}$ to $11.8 \mathrm{mg} / 100 \mathrm{~g}$. On the other hand, fruits packaged in ordinary bags and Activebags $₫$ retained higher vitamin C levels of 21.7 and $26.6 \mathrm{mg} / 100 \mathrm{~g}$ respectively. As the fruits ripened, the levels of beta-carotenes, which are responsible for the orange colour, increased gradually (Fig 6). The increase in beta-carotenes was most rapid in unpackaged fruits where beta-carotene increased from the initial $6.06 \mu \mathrm{g} / 100 \mathrm{~g}$ to $10.4 \mu \mathrm{g} / 100 \mathrm{~g}-\mathrm{a} 72 \%$ increase relative to the initial amount. On the other hand, packaged fruits had relatively lower beta-carotene levels throughout the 
storage period at the end of which the increase in ordinary bags fruits and Activebag $®$ fruits was approximately $57 \%$ and $42 \%$ respectively. Comparatively,

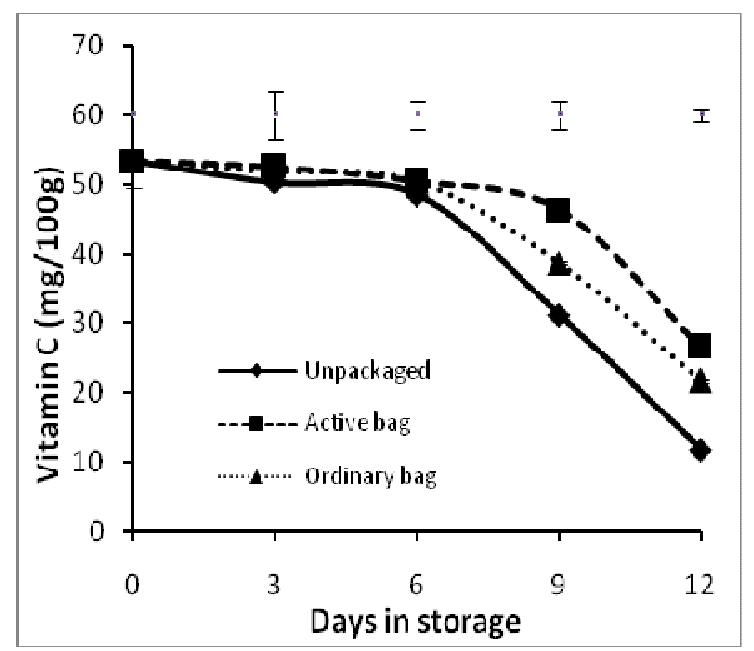

Figure 6: Changes vitamin $\mathrm{C}$ content of 'Tommy Atkins' mango fruits which were left unpackaged (control), packaged in ordinary polythene bags or Activebag®. Top bars shows least significant difference (LSD) of the means at each day of storage $(p=0.05)$.

\section{DISCUSSION}

Weight loss in harvested commodities is mainly attributed to transpiration and respiration, as the commodities are still living and continue with normal metabolic processes (Rathore et al., 2007). The consequent weight/water loss not only leads to reduction in saleable weight but also the wilted or shrivelled commodities lose their aesthetic value and are less appealing to the buyer. In the present study, although all the fruits gradually lost weight with time, the loss was more drastic in unpackaged fruits, which lost almost $12 \%$ of the initial weight at the end of the storage period, compared to $7 \%$ in the case of MA packaged fruits. Low gas and water permeability of the polymeric films used in MAP reduces the rate of water loss through transpiration (Batu et al., 1996). As a result, the internal atmosphere package becomes saturated with water vapour pressure, thereby reducing the vapour pressure deficit. Under this conditions transpiration water loss by the commodity stored under MA decreases enormously, leading to reduced weight losses as observed in the present study. Reduced respiration rate is one of the primary metabolic responses to low $\mathrm{O}_{2}$. Reduction in respiration in turn slows down the breakdown in stored energy reserves. In the present study, fruits packaged in ordinary polythene and Activebag $®$ had generally lower respiration rate compared to unpackaged controls at the end of the storage period, the unpackaged fruits had $8 \%$ more beta-carotenes than ordinary bag fruits and $17 \%$ more compared to Activebag® fruits (Figure 7 ).

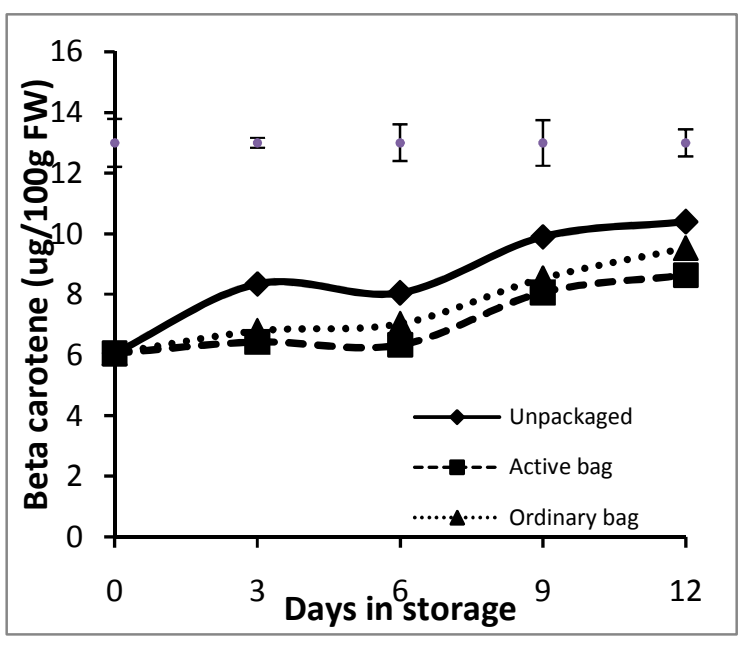

Figure 7: Changes in beta-carotene content of 'Tommy Atkins' mango fruits which were left unpackaged (control), packaged in ordinary polythene bags or Activebag $®$. Top bars shows least significant difference (LSD) of the means at each day of storage $(p=0.05)$.

throughout the storage period. Previous studies show that MA conditions may control the timing of the climacteric rise as well as the magnitude of the peak respiration. Young et al., (1962) observed a delay in the climacteric rise in avocados and bananas due to elevated $\mathrm{CO}_{2}$ levels, but only a reduction of $\mathrm{O}_{2}$ uptake at the climacteric peak in avocados. If gas diffusion is restricted to the extent that low levels of $\mathrm{O}_{2}$ and $\mathrm{CO}_{2}$ develop, undesirable effects of low $\mathrm{O}_{2}$ and elevated $\mathrm{CO}_{2}$ will result (Bender etal.2000b). In the present study both ordinary polythene and Activebag $₫$ maintained quality of the mango fruits better than unpackaged fruits. However in the case of ordinary polythene bags, off flavours occurred at the end of the storage period and there were incidents of rotting. This could be attributed to low permeability of the ordinary polythene, which may have resulted in oxygen levels below the critical level for the mango fruit thus leading to anaerobic respiration and consequent off flavours. On the contrary, Activebag ${ }^{\circledR}$ packaging no off flavours occurred and rotting was minimal at the end of the storage period. This could be attributed to the permeability characteristics of the polymeric film and impregnation with antimicrobials compounds. Erratic ethylene evolution was observed in the present study, showing no clear trend in especially in packaged fruits. Ethylene evolution increased gradually in 


\section{Githiga et al. J. Appl. Biosci. 2014 Effect of Activebag® Modified Atmosphere Packaging on the}

Postharvest Characteristics of Mango Fruits Cultivar Tommy Atkins

unpackaged fruits while in packaged fruits ethylene was only detected on the $6^{\text {th }}$ and $7^{\text {th }}$ days of storage. Conditions created in MAP (low $\mathrm{O}_{2}$ and high $\mathrm{CO}_{2}$ ) interfere with ethylene biosynthesis by hindering activity of 1-Aminocyclopropane-1-carboxylic acid (ACC) oxidase, the enzyme that catalyzes the conversion of ACC to ethylene. It has also been shown that $\mathrm{CO}_{2}$ is an antagonist of ethylene action and impedes its autocatalytic synthesis (Yang and Hoffman, 1984). Artes et al. (2006) showed that $\mathrm{CO}_{2}$ levels higher than $1 \%$ decrease or inhibit ethylene biosynthesis and consequently retard fruit ripening and deterioration, these effects being additive to those of reduced $\mathrm{O}_{2}$ atmospheres. Additionally, low $\mathrm{O}_{2}$ and elevated $\mathrm{CO}_{2}$ reduce tissue sensitivity to ethylene. The observed trend in ethylene evolution in the current study could therefore be attributed to interference with ethylene biosynthesis due to low $\mathrm{O}_{2}$ and the antagonistic action of high $\mathrm{CO}_{2}$ created under MA conditions. Softening of the peel and flesh was significantly slowed in packaged fruits compared to those that were left unpackaged. Previous studies have shown that MAP with 5-20\% $\mathrm{CO}_{2}$ and $5-10 \%$ $\mathrm{O}_{2}$ are effective in retarding softening during storage in a wide range of fruits, such as strawberries (Garcia et al., 1998), apricot (Pretel et al., 1993), kiwifruit (Agar et al., 1999), loquat (Amoros et al., 2008), peaches and nectarines (Akbudak and Eris,2004). This effect has been attributed to the reduction in activities of cell walldegrading enzymes, such as polygalacturonase under conditions of high $\mathrm{CO}_{2}$ and low $\mathrm{O}_{2}$ (Femenial et al., 1998). In the present study, the observed delay in fruit softening could therefore be attributed to reduced activity of cell wall degrading enzymes. MAP significantly delayed colour changes in peel and flesh, with the packaged fruits retaining a higher hue angle throughout the storage period. This correlated with the increase in betacarotenes, which progressed faster in unpackaged fruits. Colour changes in mango fruit are due to the disappearance of chlorophyll and the appearance yellow or red pigments (Lakshminarayana, 1980; Lizada, 1993). In yellow cultivars, carotenoids and xanthophylls are the predominant pigments. Studies in other fruits have shown that colour changes associated with the ripening process are generally delayed under MAP conditions. This has been previously reported in fruits such as mango (Pesis et al., 2002), table grape (Martinez-Romeno et al., 2003b), and loquat (Amoros et al., 2008). Delayed yellowing due to MAP has similarly been reported in vegetables such as broccoli where colour parameters significantly increased in unwrapped control broccoli during storage while MAP broccoli retained the green colour characteristic of freshly harvested broccoli after 21days of storage with chlorophyll concentration close to that found at harvest (Serrano et al., 2006). These MAP effects on colour changes, which were observed in the present study, could be attributed to the low $\mathrm{O}_{2}$ conditions that may have resulted in reduced ethylene biosynthesis. Ethylene is known to trigger the activities of enzymes involved in colour changes during ripening. These include chlorophyll oxidase enzyme involved in chlorophyll degradation (Beaudry, 2000). In addition, colour preservation by MAP storage observed in the present study could be attributed to a delay in anthocyanins and carotenoids biosynthesis, due to reduced activities of metabolic processes involved in their biosynthesis as reported by Artes et al., (2006). Packaged fruits retained relatively higher levels of TTA, TTS and soluble sugars, a rapid decrease was observed in unpackaged fruits. Citric acid is the major organic acid found in mango fruit and it decreases with ripening as it is used in respiration as a substrate (Lizada, 1993). Therefore, the higher the rate of respiration observed may have contributed to faster the consumption of substrates such as citric acid hence the rapid decrease in TTA observed. On the other hand, low $\mathrm{O}_{2}$ in MAP associated with lower respiration rate could explain why packaged fruits retained higher TTA (expressed as citric acid \%) throughout the storage period. Similar results were obtained by (Almenar et al., (2008) on strawberry packed at low level of $\mathrm{O}_{2}$ where the level of acidity was high during storage. Packaged fruits retained relatively lower levels of TSS throughout the storage period. Just like TTA, changes in TSS were closely correlated to respiratory activity. The level of ascorbic acid decreased with storage time in all the treatments with the Activebag $®$ and ordinary bag fruits retaining relatively higher levels throughout the storage period. Ascorbic acid is a water-soluble vitamin and previous studies have shown that transpiration water loss is associated with loss of water soluble vitamins including vitamin C (Valero and Serrano, 2010). In the present study, the water loss and ascorbic acid reduction followed a similar trend with unpackaged fruits (with the most rapid cumulative weight loss) recording the highest loss in ascorbic acid. The loss in ascorbic acid loss was slowed down by MAP in Activebag ${ }^{\circledR}$ and ordinary polythene bags. On the contrary, studies in fresh-cut kiwifruit slices kept under MAP conditions with high level of $\mathrm{CO}_{2}$ showed faster degradation of vitamin C (Agar et al., 1999). Other studies also show that Ascorbic acid during storage is susceptible to oxidative destruction at ambient storage conditions (Aina, 1990). 


\section{CONCLUSION}

Modified atmosphere packaging (MAP) is a simple postharvest technology that could be easily adopted even by small-scale farmers to minimize postharvest losses in mango fruits. If the commodity characteristics are properly matched to the package's permeability characteristics, an appropriate modified atmosphere can passively evolve within a sealed package. The environment so created can significantly delay ripening in mango fruits by slowing down or delaying most of the ripening related physiological and physicochemical changes thereby extending the marketing period of the fruits. However, when the commodity and package characteristics are not matched to attain a favourable inpack environment, the negative effects such as offflavours and rotting, as observed in the case of ordinary polythene packaging, offset the benefits of MAP.

\section{ACKNOWLEDGEMENT}

This research was funded by National Commission of Science Technology and Innovation

\section{REFERENCES}

Agar IT, Massantini R, Hess-Pierce B, Kader AA, 1999. Postharvest carbon dioxide and ethylene production and quality maintenance of freshcut kiwifruit slices. Journal of food science 64 : 433-440.

Aina JO, 1990. Physiochemical changes in African mango (Irvingia Gabonensis) during normal storage ripening. Journal of Chemistry 36: 205 212.

Akbudak B, Eris A, 2004. Physical and chemical changes in peaches and nectarines during the modified atmosphere packaging storage. Food control 15:307-313.

Almenar E, Pilar H, Valeria D, Dinoraz V, Rafael G, 2008. Effect of chitosan coating combined with postharvest calcium treatment on strawberry (fragana and ananassa) quality during refrigerated storage, food chemistry 110:428435.

Amoros A, Pretel MT, Zapata PJ, Botella MA, Romojaro $F$, Serrano, M, 2008. Use of modified atmosphere packaging with microperforated polypropylene films to maintain postharvest loquat quality. Food science and Technology International, 14:95-103

Artes-Hernandez F, Tomas-Berberan FA, Artes F, 2006. Modified atmosphere packaging preserves quality of SO2-free'Superior seedless' table Grapes. Postharvest Biology and technology 39: 146-154

Batu A, Thompson K, 1996. Effects of Modified Atmosphere Packaging on Post-harvest Qualities of Pink Tomatoes. Journal of Agriculture and Forestry 22:365-372.

Beaudry RM, 2000. Responses of horticultural commodities to oxygen: Limits to the expended use of modified atmosphere packaging. Hort. Technology 10: 491-500.

Bender RJ, Brecht JK, Sargent SA, Huber DJ, 2000b. Low temperature controlled atmosphere packaging and controlled atmosphere storage. In: Environmentally friendly technologies for agricultural produce quality. Ben-Yehoshua, S. Ed. Taylor and Francis Group LLC. BocaRato, FL, USA. Chapter 4.

Femenia A, Sanchez ES, Simal S, Rosello C, 1998 Modification of cell wall composition of apricot (Prunus armeniaca) during drying and storage under modified atmospheres. Journal of Agricultural and Food Chemistry, 46:5248-5253.

Lakshminarayana S Mango. In: Nagy, S. and Shaw, P.E, 1980. (Eds) Tropical and Subtropical Fruits. AVI Publishing Co. Westport, Connecticut, pp. 184257.

Lizada C. Mango in symur G.B., Tyler, JE and Tucker, G.A, 1993. (Eds).Biological of fruit ripening, Chapman and hall, lodon, pp255-271.

Martinez-Romeno D, Guillen F, Castillo S, Valero D, Serrano M, 2003b. Modified atmosphere packaging maintains quality of table grapes. Journal of Food Science, 68:1838-1843.

Omry K, 2011 Postharvest Manager, Amiran Kenya Limited. Personal Communication,

Pesis E, Eckerman M, Ben-Arie R, Feygenberg O, Feng X, Apelbaum A, Goren R, Prusky D, 2002. Ethylene involvement in chilling injury symptoms of avocado during cold storage. Postharvest Biology and Technology, 24:171-181.

Pretel MT, Serrano M, Martinez G, Riquelme F, Romojaro $F, 1993$. Influence of films of different permeability on ethylene synthesis and ripening of MA-Packaged apricots. LebensmittelWissenschaft and Technology, 26: 8-13. 
Prusky D, Kee NT, 1993. Involvement of preformed antifungal compounds in the resistance of subtropical fruits to fungal decay. Plant Disease, 77:144-119.

Rathore HA, Masud T, Sammi S, Soomro HA, 2007. Effects of storage on physico-chemical composition and sensory properties of mango (Mangifera indica L.) var. Dosehari. Pakistan Journal of Nutrition, 6: 143-148.

Serrano $M$, Martínez-Romero $D$, Guillén $F$, Castillo $S$, Valero D, 2006. Maintenance of broccoli quality and functional properties during cold storage as affected by modified atmosphere packaging. Postharvest Biol. Technol. 39, 61-68.

Singh, Rao DVS, 2005. Effect of modified atmosphere packaging (MAP) on the alleviation of chilling injury and dietary antioxidants levels in 'Solo' papaya during low temperature storage. European Journal of Horticultural Science, 70: 246-252.

Slaughter DC, 2009. Non-destructive maturity assessment methods for mango: A review of Literature and Identification of Future Research Needs,

Valero D, Serrano M, 2010. Postharvest biology and technology for preserving fruit quality. pg 162173.

Yahia EM, 2006. Modified atmosphere for tropical fruit, Stewart postharvest Review, 5:6

Yang SF, Hoffman NE, 1984. Ethylene biosynthesis and its regulation in higher plants. Annual Review of plant physiology, 35:155-189.

Young RE, Roman RJ, Biole, 1962. Carbon dioxide effect of fruit respiration. Response of avocados, banana and lemons. Plant Physiol. 37:416-422. 